\title{
Biología de la memoria
}

\author{
Marcelino Cereijido
}

Este capítulo resume escuetamente lo que la biología ha aprendido sobre la memoria. La ciencia considera que la realidad no está integrada por cosas, sino por procesos. Todo lo que vemos, desde una nube hasta una galaxia, no son más que configuraciones pasajeras, aunque las primeras sean efímeras y las segundas duren millones de millones de años. En este sentido, la memoria depende de recuerdos transitorios que atribuimos a procesos mentales, y de estructuras cerebrales cuya forma actual es el resultado de miles de millones de años de evolución, pero que también son procesos, sólo que han adoptado configuraciones espaciales muy estables, pues duran toda nuestra vida, y se repiten en todos los humanos y aun en otras especies biológicas. Desconocemos de qué manera esa información es memorizada en eterno presente, y cómo hacemos para atribuir un contenido dado a un tiempo pasado o proyectarlo hacia el futuro. Se sospecha que el reservorio informativo puede estar contenido en el agua neuronal. Solo una parte irrisoria de la memoria ha pasado a ser consciente en los últimos 50-100 000 años de la historia de los humanos en la Tierra. Este lapso representa apenas un cuarentamilésimo de la existencia de vida en el planeta. El resto se maneja con una dinámica que desconocemos, pero que parece tener la facultad de hacerse consciente en el momento en que "él lo desee" o "disponga", como si lo determinara autónomamente él mismo; en cambio, el dominio consciente no parece tener forma de acceder libremente al colosal patrimonio cognitivo inconsciente. Uno de los problemas más formidables que se presentan para "entender" la memoria, es que tendríamos que explicar racionalmente procesos que son preponderantemente inconscientes, que no se rigen por la lógica clásica, y en los que participan sensaciones y emociones que por ahora nos resultan indescifrables.

This chapter summarizes what Biology has to say about memory. Science considers that reality is not a collection of things, but of processes. Everything we see, from a cloud to a galaxy is process, regardless of whether the first is ephemeral, and the second lasts millions and millions of years. In this sense, memory depends on transient events that we attribute to mental processes, and cerebral 
structures whose present form is the result of thousands of millions years of evolution, but that nevertheless are processes, only that have adopted spatial configurations which are stable, as they can last all our life, and that are repeated in every human as well as in other biological species. We ignore how information is memorized in eternal present, and what do we do to attribute a given event to the past or to the future. It is suspected that the reservoir of information can be stored in the water contained within neurons. Only a tiny amount of what memory contains is or can be made conscious. Conscience has appeared in the last 50-100 thousand years of human history, which is only $1 / 40.000$ of the existence of life on Earth. Unconscious memory operates with an unknown dynamics, but we know that it can become conscious whenever "it decides so", as if ruled by an autonomous wish. On the contrary, the conscious domain does not have the power to access every part of unconscious memory that we may wish. One of the most formidable problems posed by the understanding of memory, is that we would have to explain in a rational (conscious) manner a series of processes which are mainly unconscious, that do not seem to be ruled by classical logic, and where feelings and emotions seem to play a paramount role. 
Marcelino Cereijido

Centro de Investigación y de Estudios Avanzados, IPN

\section{Biología de la memoria}

La mayoría de los ensayos expuestos en este volumen se refiere a una memoria humana ya dada, para cuyo tratamiento no presenta mayor inconveniente el dar por sentado que el ser humano ha sido creado tal como lo vemos hoy día, y que el conocimiento científico arrancó hace unos 2500 años en Babilonia, Egipto y Grecia, con pensadores blancos, europeos, del sexo masculino y que ya nacen adultos. Por el contrario, como yo me referiré a la biología de la memoria, necesito dar a mi exposición un enfoque evolutivo.

Dos memorias fundamentales

La primera memoria, la genética, permite que el hijo del lagarto sea un lagarto y el del caballo un caballo, y no al revés. Está contenida en el DNA, que sólo contiene información, que por sí misma no significa nada, y sólo se vuelve capaz de generar un lagarto o un caballo cuando se la pone en condiciones de funcionar de una cierta manera. Esa "cierta manera" es el contexto celular en el que existen baterías de enzimas capa- 
ces de procesar el mensaje genético, y que se gesta dentro del organismo materno. La biología ya ha aprendido a tomar un ovocito (la célula resultante de la fusión de un huevo con un espermatozoide), quitarle su núcleo, remplazarlo con el núcleo de una célula somática de oveja, y hacer que la información del DNA nuclear produzca una nueva oveja, con un cerebro que tendrá como atributo albergar y hacer funcionar el segundo tipo de memoria biológica fundamental: la memoria mental de una oveja.

En este Seminario ${ }^{1}$ nos interesan solamente las memorias del segundo tipo, el mental, pero es bueno ir tomando nota de que la memoria genética está almacenada en una estructura molecular y que la biología ya sabe cómo hacerla funcionar para que se exprese y ejecute lo que sabe (hacer una oveja). En cambio, la elucidación de las memorias mentales presenta todavía problemas formidables.

\section{Hacer y entender en biología}

Todos los organismos, sean vegetales o animales, necesitan una manera de interpretar la realidad. La ameba "entiende" que esa pequeñísima partícula flotando a cuatro micrones de distancia es una bacteria, y cumple los procesos necesarios para fagocitarla. El pulpo "reconoce" que eso que cruza su campo visual horizontalmente es un pez, significa "alimento", y desencadena un reflejo casi explosivo para atraparlo. La flor carnívora "interpreta" que eso que se ha posado en sus pétalos es un insecto, vale la pena cerrarlos, atraparlo y nutrirse. Aquí "reconocer", "interpretar" y "entender" se reducen a constatar que las señales que llegan de la bacteria, el pez y el insecto concuerdan con cierta memoria que la ameba, el pulpo y la

\footnotetext{
${ }^{1}$ El Seminario Interdisciplinario del PROMEP "Políticas de la memoria".
} 
flor tienen de ellos, y bastan para provocar una respuesta específica para devorarlos. En cuanto a si la ameba, el pulpo y la flor entienden que están entendiendo, carece de importancia para esta etapa de nuestra presentación. ${ }^{2}$

A medida que los organismos se van haciendo más complejos, las respuestas para lograr un fin pasan de ser fijas, a tolerar un cierto grado de ambigüedad cada vez más alto, y requieren un sistema nervioso más avanzado para escoger la manera de responder más satisfactoria. Así, una banana no se esconde ni tiene estrategias de fuga, en cambio un pájaro, un ratón y una gacela eluden a quien trata de atraparlos, por lo que nos parece obvio que un carnívoro tenga más cerebro por kilo de peso que un herbívoro. Los organismos más complejos pueden incluso presentar un creciente grado de socialización en la tarea de cazar y procurarse comida, y eso selecciona individuos capaces de captar señales de otros miembros del grupo, desentrañar los modelos mentales del otro, y coordinar el contenido de las memorias ajenas.

Para generar novedades, la Naturaleza suele aprovechar estructuras y cualidades que ya posee y darles nuevas formas y usos. Esto se capta fácilmente en la transformación de las patas delanteras de una langosta en pinzas, o en la producción de alas de murciélago a partir de las patas delanteras de un ratón. Un ejemplo de ese aprovechamiento de cualidades que ya se tienen "para"3 generar novedades evolutivas, es cuando las habilidades de caza se extienden para luchar y guerrear.

También la vida humana depende de que se interprete la realidad correctamente, sólo que la selección de sentidos temporales

${ }^{2}$ Afirmación demasiado radical, limitada al punto en discusión. En realidad la biología de la conciencia, sobre todo su filogenia, sus bases neurobiológicas y sus repercusiones psiquiátricas ocupan un lugar muy destacado en los esfuerzos actuales. Para una excelente y accesible descripción de este tópico véase Damasio 1999.

${ }^{3} \mathrm{La}$ ciencia no admite explicaciones teleológicas porque un efecto futuro no viaja en sentido contrario al tiempo ni provoca una respuesta presente. El uso de "para" se tolera por mera conveniencia didáctica. 
capaces de abarcar más y más futuro multiplica enormemente el número de opciones, y esta riqueza de posibilidades se convierte en una arena de prueba y selección de cerebros e inteligencias más poderosas. Las ventajas que brinda el escoger hicieron de la inteligencia algo muchísimo más valioso para el humano que el garrote y la piedra cortante. Una idea muy clara de la relación entre memoria, capacidad de combinar contenidos de memoria e imaginar alternativas para escoger la más adecuada, lo da el hecho de que la primera vez que un campeón mundial de ajedrez, Garry Kasparov, pierde un partido contra una computadora, es cuando se fabrica la famosa Deep Blue, capaz de analizar del orden de los cien millones de jugadas antes de decidir su próxima jugada. Es probable que la conciencia se haya ido desarrollando como una herramienta para aprovechar ambigüedades y sumar en paralelo las memorias ajenas, coordinando la respuesta con las habilidades de otros miembros del grupo. Huelga decir que a su vez esto ayudó a forjar y a seleccionar el lenguaje. El humano sólo fue entendiendo las cosas que le resulta imprescindible entender; pero ningún hombre de Neanderthal, ningún Cromagnon, ningún babilonio necesitó enterarse de que su organismo "sabe" regular su glucemia, ni de que la disminución de la concentración de azúcar en sangre activa centros nerviosos que le hacen sentir hambre; le bastó saber cazar, recolectar y comer cuando sentía hambre.

Advirtamos que la memoria se refiere a algo pasado, pero va a ser evaluada (seleccionada o extinguida) por su utilidad para operar en alguna situación futura que se repite. Volviendo a Kasparov y Deep Blue, el maestro la derrotó cuando apeló a estrategias novedosas, que no habían sido introducidas previamente en la memoria de la máquina. De manera que si bien la memoria sirve para rememorar el pasado, deleitarse con un recuerdo, analizar nuestra performance y perfeccionarla, es primordialmente una herramienta para sobrevivir en el futuro. 
Justamente, el virus del sarampión nos dejó una memoria inmunitaria útil, que lo reconocerá y llevará a anularlo en una futura epidemia; por el contrario, el de la influenza traerá un repertorio molecular distinto al de la epidemia de gripe pasada, no será reconocido por nuestros anticuerpos y volverá a enfermarnos. Kierkegaard opinaba que la vida se vive para adelante, pero sólo se la entiende mirando para atrás, y García Márquez señalaba que la vida no es lo que uno vivió, sino lo que uno recuerda. Vayamos entonces teniendo en cuenta estos juegos del sentido temporal.

\section{Evolución en la manera de interpretar la realidad}

Como todas las cosas de este mundo (estrellas, continentes, utensilios, ropas, organización social), la manera humana de interpretar la realidad fue heredada de la memoria biológica de especies ancestrales, y luego, ya convertida en memoria humana, ha continuado evolucionando. Seguramente la Evolución lo ha hecho como acostumbra, esto es, desechando ("extinguiendo", como si se tratara de una especie biológica) las interpretaciones chapuceras ("No creo que este hongo sea venenoso", "Aquellos leones perezosos parecen distraídos e inofensivos") y optando por interpretaciones provechosas ("Este trozo de carne que quedó cerca del fuego, no se ha podrido en varios días ¿Acaso el fuego impide que se vuelva tóxico?", "Si como papas me enfermo, pero cuando como papas que quedaron cerca del fuego puedo sobrevivir una hambruna"4).

Esa Evolución ha ido superando las maneras de interpretar la realidad que brindan los modelos animistas en favor de modelos de magia, chamanismo, politeísmo, monoteísmo, hasta que hace muy poco tiempo (tres o cuatro milenios no son nada

\footnotetext{
${ }^{4}$ La papa es una verdadera bomba de diazepán, cuya molécula es termolábil.
} 
evolutivamente hablando) ha generado el modelo de la ciencia moderna. Así tomada, la ciencia moderna no es más que el último modelo de la manera humana de interpretar el mundo en que vivimos. Consiste en interpretar sin invocar milagros, revelaciones, dogmas ni el principio de autoridad, por el cual algo es verdad o mentira dependiendo de quién lo diga (la Biblia, el papa, el padre).

Cuando un modelo incluye la variable tiempo, hablamos de modelos dinámicos. El siglo XIX ha sido llamado "Siglo de la Dinámica" porque los sabios de las distintas disciplinas no se contentaron con entender el mundo tal como es, sino que intentaron explicarse cómo ha llegado a ser de esta manera que observamos en el presente. Los geólogos ya no se conformaron con estudiar la distribución y altura de las montañas y las propiedades de los ríos, ahora querían encontrar los modelos dinámicos que originan montañas y ríos, y descubrir los mecanismos $^{5}$ implicados. Y así los economistas propusieron modelos dinámicos para explicar por qué hay pobres, ricos, clases; los patólogos se esforzaron por entender las enfermedades a través de los agentes y procesos que las causan; los psicoanalistas exploraron crianzas y neurosis; los cosmólogos estrellas. Esa tendencia a interpretar el presente como consecuencia de un pasado dinámico llevó a la biología a entender por qué hay pinzones, monos y seres humanos. En la misma filosofía, Hegel hace del tiempo una variable fundamental de su sistema. En el siglo XIX el Universo, pasó de ser interpretado como una cosa, a ser visto en cada momento como el estado actual de un proceso $^{6}$ comenzado hace 15000 millones de años con formidable reventón.

${ }^{5}$ La Física era la reina de las ciencias y una de sus ramas más prominentes y prestigiosas era la Mecánica. Las otras disciplinas sintieron que si llamaban "mecanismos" a los procesos que estudiaban, adquirían un estatuto más científico.

${ }^{6} \mathrm{La}$ función es aquel proceso que tiene un sentido. Por ejemplo, una radio tiene la función de recibir sonidos, pero puede sufrir muchos otros procesos: romperse, oxidarse, hacer de pisapapeles. Con todo, la noción de sentido depende del obser- 
Sin embargo, los mismos biólogos, herederos de una dicotomía cuerpos/almas, han operado casi hasta nuestros días con la dualidad anatomía/fisiología. Es que un hígado, un corazón, un hueso son estructuras que permanecen ahí, aparentemente imperturbables durante su función, y ahí siguen hasta en la mesa de autopsias. Pero dicha estabilidad sólo se mantuvo mientras las inspecciones del biólogo se limitaban a la macroscopía. El advenimiento de la microscopía muestra alteraciones serias que ocurren cuando cesa la vida y, cuando la microscopía se extiende hasta la que se realiza con microscopios electrónicos, se observa fácilmente que en cuanto se suspende la vida se pierden las estructuras más delicadas y fundamentales, como flagelos, mitocondrias, microfilamentos, microtúbulos, vesículas endocíticas, receptores hormonales. Gran parte de la pericia del biólogo radica en el uso inmediato de fijadores de veloz penetración (por ejemplo, el glutaraldehído), que junto con la inmediata congelación y el uso de poderosos inhibidores metabólicos evitan que las enzimas destruyan esos organelos. Se constata así que las células tienen "cosas" que, si bien no pueden observarse a simple vista y desaparecen rápidamente al detener el proceso biológico, como se extingue el hongo de agua en cuanto se apaga la bomba hidráulica de la fuente, son tan "estructuras" como un fémur, una costilla o una glándula sudorípara. Resulta mucho más fácil determinar si se está frente al cadáver de un atleta, que frente al cerebro de un matemático, en qué idioma habrá hablado, o cuál habrá sido su ideología, porque estas cualidades dependen de configuraciones (estructuras) muchísimo más sutiles y efímeras.

vador y es discutible. Así, si me pagan para estudiar qué le sucede a una radio dejada a la intemperie, para saber con qué materiales construirla, no tiene sentido que alguien se apiade del aparato, lo limpie, lo componga, lo eche a andar, e interrumpa mis estudios. Véase Cereijido 1980. 
Una de las preguntas que trata de resolver la biología de la memoria, es en qué estructura está almacenada nuestra memoria, en cuáles el rostro de nuestra madre, el aroma del chocolate y el vals Sobre las olas.

Para entender las bases y los mecanismos de la memoria, la ciencia fue recurriendo a las analogías que iba teniendo a mano. Cuando la forma más avanzada de registrar era la escritura, pensó que la memoria consiste en una colosal biblioteca; luego, con el desarrollo de la fotografía, imaginó la memoria como un álbum fotográfico, incluso "tener una memoria fotográfica" se sigue usando como metáfora. Más tarde, el desarrollo de las calculadoras mecánicas llevó a pensar la mente como un complejísimo mecanismo de relojería $\mathrm{y}$, última e inevitablemente, se piensa en mecanismos de computación, holografía y procesos cuánticos. Sin embargo, una cosa es dar por sentado que, puesto que los procesos moleculares y atómicos en los organelos de una neurona se cumplen a escalas del nanómetro (un nanómetro es $10^{-9}$ centímetros: una milésima de milésima de milímetro), deben necesariamente obedecer las leyes de la mecánica cuántica, y otro muchísimo más difícil es especificar cómo funciona.

Sabemos que un microcircuito de computadora, de apenas unos centímetros cuadrados, puede almacenar la memoria de un hospital, incluidas las historias clínicas de todos sus pacientes, tratamientos, costos y colecciones de revistas que consultan sus médicos, fotos y currículum vitae del personal. Esos portentos dependen de la magnetización y cambios de magnetización de micropartículas (hardware) en respuesta al paso de pulsos eléctricos comandados por programas (software). Pero esas micropartículas son verdaderos cascotes amorfos comparados con la pequeñez de las moléculas de agua, ${ }^{7}$

${ }^{7}$ La molécula de agua es eléctricamente neutra, pero sus cargas eléctricas no están distribuidas homogéneamente sino que un extremo es negativo y otro posi- 
que son como brujulitas electromagnéticas que cambian su orientación y relación entre ellas, como cambian su orientación y relación entre ellos un conjunto de alfileres cuando se les acerca un imán. Por eso, y por la cercanía de microfilamentos y membranas, el agua de una neurona no está líquida, sino que forma estructuras similares a las que forma en el hielo, sólo que no lo hace necesariamente por debajo de cero grados, sino a la temperatura corporal. Esas configuraciones del agua son sensibles a la presencia de iones, al signo de su carga (positivo o negativo), al contacto con las porciones hidrofóbicas o hidrofílicas de las moléculas orgánicas del cerebro, y todos esos arreglos espaciales cambian y se reconfiguran en respuesta al relampagueo de potenciales eléctricos que viajan por billones de circuitos neuronales, saltan de una neurona a otra, se suman, restan, y provocan la liberación y captación de mediadores químicos (serotonina, GABA, glutamato, acetilcolina, endorfina, etc.). Por eso la sutil complejidad de los arreglos moleculares del agua cambia cuando se recuerda una melodía, se habla, se decide ir a dormir y se sueña, de manera análoga a la que cambia la estructura de un disco compacto cuando le grabamos una canción o un poema, o cuando, ya grabado, se lo perturba para que sus estructuras vibren y nos devuelvan el sonido. Sólo que en el caso de los circuitos cerebrales las configuraciones no son estáticas, sino que cambian a velocidades difíciles de imaginar, día y noche, durmamos o estemos despiertos, contentos o amargados, concentrados en un teorema o mirando en lontananza.

Conviene complementar estos conceptos señalando que cuando una función es muy importante y habitual a lo largo de

tivo (decimos que forman un dipolo). Más aún, la magnitud de ese dipolo se incrementa cuando la molécula de agua se acerca a una carga eléctrica. El fenómeno puede visualizarse con una analogía sencilla: los alfileres desparramados sobre una mesa que de pronto son atraídos por un imán, y pasan a atraerse entre sí formando una suerte de estructura. 
millones de años, la Evolución va seleccionando órganos más y más perfeccionados para ejercerla. La memoria es tan crucial para el humano, que se han ido seleccionando los organismos que poseen procesos/estructuras que favorecen el manejo de una cantidad cada vez mayor de información. Pero un organismo tan simple como el caracol (comparado con el humano, claro), al que se le pasa un tren de estímulos eléctricos por cierto circuito neuronal, primero cambia su respuesta ante la repetición del patrón de estímulos, y luego aumenta o disminuye el número de botones sinápticos como consecuencia de la habituación y el aprendizaje, es decir, los incluye en una memoria primero puramente funcional, pero que luego se refleja en una clara modificación estructural del sistema nervioso. No extraña entonces que el cerebro humano tenga una serie de conexiones y núcleos de cuya integridad depende la memoria.

En un primer momento se trató de localizar el centro que actúa específicamente como reservorio cognitivo, y se logró identificar los más importantes (por ejemplo el hipocampo, la corteza frontal), sobre todo porque aparecen dañados en la autopsia de pacientes que presentan alteraciones de varios tipos de memoria, que van desde el olvido de números y nombres, al de su propia identidad. Hoy se cuenta con una serie de técnicas no invasivas, en las que se puede ver qué regiones del cerebro se encienden o apagan cuando se recuerda algo a pedido del experimentador (¿En qué barrio nació? ¿Cómo se llamaba su maestra de primer grado?) o cuando el sujeto los trae a colación espontáneamente. La circuitería nerviosa es tan compleja y dinámica que me resisto a desviar la atención hacia una descripción aunque sea somera. Baste con decir que, también en un principio, se sospechó que las mismas áreas sensibles del cerebro eran las que almacenaban los datos; por ejemplo, que la región de la cisura calcarina del lóbulo occipital a la que van a parar las vías ópticas, era la responsable de re- 
cordar las cosas que se habían visto. Tras constatar que hay pacientes que pueden reconocer algo visto previamente, pero no pueden nombrarlo, o al revés, pueden nombrar algo pero no reconocerlo, o que padecen amnesia a pesar de que tienen la cisura calcarina indemne, y otras situaciones por el estilo, se concluye que prácticamente no hay zona del cerebro ajena a la memoria, si bien hay, como digo, áreas y núcleos que parecen ser más cruciales; pero incluso pueden serlo no porque sean reservorios informativos, sino por el mero hecho de que conectan estructuras cardinales.

Hay otros dos tipos de conocimientos que han ido surgiendo independientemente, y que nos pueden ayudar a captar los esfuerzos por entender las bases biológicas de la memoria. 1) El primero se basa en el concepto de sistema complejo. Se trata de sistemas con un número muy grande de componentes, de distinta naturaleza (por ejemplo la salud es un sistema complejo, en el sentido de que intervienen conocimientos médicos, culturales, laborales, económicos, etc.), cada uno de los cuales es estudiado por una disciplina distinta (medicina, sociología, economía, etc.). En un sistema complejo cada causa origina más de un efecto y cada efecto obedece a varias causas. Por otra parte, la relación causa $\rightarrow$ efecto no es lineal, sino que cuando las causas llegan a cierta intensidad provocan crisis estructurales/funcionales. Dada la enorme complejidad de estos sistemas, podríamos sospechar que cuando se desencadena una crisis, va a suceder "cualquier cosa". Sin embargo se observa que los sistemas complejos caen en "atractores", es decir, pautas conductuales en las cuales sólo se atrapa un número comparativamente irrisorio de alternativas. Por ejemplo, dado el número tan grande de genes, enzimas y componentes químicos de una célula, uno podría imaginar que puede producirse un número prácticamente infinito de tipos celulares. Por el contrario, no existen más que unos 300 tipos celulares distintos (fibroblastos, mielocitos, neuronas, osteocitos, mio- 
citos, etc.). Concomitantemente, ante una situación dada, los sujetos no suelen presentar infinitas respuestas, sino que todos caen en una de entre un número irrisorio de ellas (pelea/huye, ríe/teme, atiende/se distrae). 2) El otro cúmulo de conocimientos está surgiendo del estudio de circuitos neuronales. Estos circuitos pueden ser reales (acabamos de referirnos a cierto circuito del caracol que muestra memoria y plasticidad), o ser simulados por computadoras. El estudio de los componentes y conductas de estos circuitos constituye hoy una nueva disciplina.

Para finalizar este subcapítulo, señalemos que el mismísimo cerebro ha perdido el monopolio absoluto del conocimiento y los recuerdos. Se demuestra, por ejemplo, que el cerebro influye sobre los órganos que captan las sensaciones (táctiles, dolorosas, térmicas, etc.), de modo que, para cuando le llegan los impulsos correspondientes, ya han sido filtrados, procesados en parte, y hasta podríamos decir que los recibe con cierto grado de "interpretación". Para revisar un accidentado que ha sufrido un traumatismo en la espalda y que se ha afectado la columna vertebral, los neurólogos usan un alfiler de gancho y solicitan que, sin mirar, el paciente vaya diciendo si lo toca con la punta roma o lo pincha con la aguda, pues la primera depende de la sensibilidad táctil y la segunda de la dolorosa. Explorando de este modo la superficie del cuerpo del accidentado, el neurólogo puede ir precisando la altura y la gravedad de la lesión medular. Se han detectado pacientes que son capaces de especificar correctamente "toca", "pica" siempre que se les avise "voy a explorar tocándolo (o picándolo)", pero no si se les omite esta información. El cerebro sabe qué circuitos poner en juego en uno u otro caso, mecanismo aludido en la frase popular "prestar atención”. Parece haber memorias (¿capas, sótanos?) que no pueden hacerlo (los estratos profundos del inconsciente), pero todavía no sabemos cuáles son los trámites de ingreso a una $u$ otra. 


\section{El cerebro prehistórico}

Los biólogos no podemos limitarnos a lo sucedido en los últimos tres mil o cuatro mil años de historia, pues antes de la Revolución Agraria (hace unos diez mil años) cuando el ser humano era apenas un cazador nómada, ya tenía un cerebro con las siguientes propiedades: a) sabía generar modelos dinámicos de la realidad (imaginar todo lo que podría ocurrir en una situación dada, y jugar mentalmente con esos modelos para escoger la alternativa más promisoria acerca de cómo le convenía proceder); b) tenía una memoria formidable, preponderantemente inconsciente; c) captaba duraciones con una flecha temporal de pasado a futuro, y que ya hemos llamado sentido temporal; d) transformaba el tiempo real en tiempo mental (podía por ejemplo narrar su vida en unos minutos, o pasarse el resto de sus días describiendo y volviendo a describir un fenómeno que lo había impresionado cuando tenía 15 años de edad, pero que apenas había durado fentosegundos; por ejemplo un rayo que había matado a su compañero parado a medio metro); e) tenía un lenguaje; f) así como las plantas son seleccionadas por su capacidad de fotosintetizar y las vacas lo son por la de digerir celulosa, el hombre había hecho del conocer su herramienta evolutiva, y era seleccionado con base en dicha capacidad; g) la Evolución había seleccionado a un ser humano creyente, pues otorga una enorme ventaja que no sólo incorporemos lo que nosotros mismos hemos visto y oído, sino lo que nos narraron nuestros padres, maestros y la sociedad entera; ${ }^{8}$ h) también había venido evolucionando la manera en que ese Homo sapiens creyente transmite socialmente su patrimonio cognitivo a través de la crianza y la docencia.

Frente a estos portentos epistemológicos, el hecho de que hace tres mil o cuatro mil años babilonios, egipcios y griegos

\footnotetext{
8 "No hay hombre que, fuera de su especialidad, no sea crédulo." Véase Borges 1956 y $1956 a$.
} 
desarrollaran la filosofía, la geometría y la astronomía es casi una intrascendencia.

\section{Origen evolutivo del creyente}

El individuo y la sociedad se van constituyendo mutuamente en una maraña de interacciones en la que no nos detendremos. En cierto modo, creer es incorporar información de la memoria ajena, sin un filtro "personal" o, mejor dicho, uno que nos ha colocado la cultura a través de la crianza y la educación. Si el conocer y el entender son cruciales para el ser humano, es enormemente ventajoso que se seleccionen individuos que no solamente incorporen a su patrimonio cognitivo lo que ellos aprendieron directamente, sino lo que aprendió toda la sociedad. Por ejemplo, yo no conversé jamás con Amenofis IV, ni presencié las campañas de Alejandro Magno, ni sé cómo se forman los arrecifes coralinos, ni produje el idioma castellano; pero adquirí todos esos conocimientos porque se los fui creyendo a mis padres y maestros. Comparto con los animales el enterarme de ciertos peligros y ventajas con sólo observar la conducta de mis congéneres... y no tan congéneres, pues puedo advertir que algo está alarmando al perro y espantando los pájaros. La ventaja de esta función es tan antigua, que ya está plasmada en estructuras cerebrales. En una escena de la película $E l$ Dr. No (Dr. Strangelove) aparece una tremenda tarántula que marcha sobre la almohada rumbo a la cara de James Bond que, obviamente, se aterra en cuanto la detecta. Se asusta porque tiene cierta área cerebral que le permite reaccionar aunque jamás lo haya picado una araña. También se horripila el público en el cine, porque se le activa la misma estructura cerebral. Más aún, es probable que el lector de este texto sienta repulsión porque también se le activa dicha área con sólo leer el párrafo. Además, quien nos narra un 
suceso suele enarcar las cejas, llevarse las manos a la cabeza, sonreír, encogerse de hombros, desdeñar, entusiasmarse en el relato, hablar lacónicamente, llorar, que se transforman en señales significativas para la forma en que hemos de registrar el hecho. Pero no por eso guardamos dicho conocimiento tal y como lo recibimos, sino que cada uno de nosotros lo vuelve a filtrar e interpretar de manera distinta, de acuerdo con el lugar del suceso, nuestra historia y las vivencias previas, acaso experiencias infantiles, relatos y experiencias de nuestro pueblo, de nuestra ideología y dependiendo también de a quién y para qué lo estamos relatando.

... Pero ahora nos piden un relato racional, lineal y sobre todo veraz

Advertimos entonces que las memorias no se enriquecen y se evocan exclusivamente a través de narraciones neutras, sin emoción, y que tampoco es fácil racionalizar las emociones, como es el caso de la tarántula del ejemplo anterior. De pronto el aroma de cierta comida, o cierto perfume, son muchísimo más eficaces en rememorar una escena infantil o un romance que una novela de dos tomos. A pesar de que nuestra memoria guardó —no sabemos cómo- datos concretos (un número de teléfono, un nombre), olores, temores, experiencias, sincronías y diacronías, y luego los combinó, resignificó y retuvo/ olvidó selectivamente, ahora nos piden que narremos algo específico (¿Cómo fue?), es decir, que hagamos una reedición, simplificación, ordenamiento cronológico del relato, enfaticemos, gesticulemos. Esas piezas de la narrativa no estaban ordenadas a lo largo de un tiempo calendárico ni cronométrico, y durante el relato tendremos "presente" que estamos hablando con un partisano/represor. De todos modos, si la narración es eficaz, logra que el destinatario "reviva" aquellos momentos, 
se trate de un relato oral, teatro, poesía, novela u otra forma de expresar nuestra memoria.

\section{Biología del tiempo}

En este texto hemos estado aludiendo al tiempo de varias maneras. Hasta ahora nadie ha realizado experimento físico alguno que demuestre la existencia de lo que llamamos tiempo. ${ }^{9} \mathrm{El}$ tiempo tampoco existe en la memoria. Podemos sentir nostalgias al escuchar una vieja canción de Carlos Gardel, muerto hace más de medio siglo, pero se trata de un efecto presente, causado en este momento por la perturbación de una cierta estructura presente como en un disco compacto, fabricado acaso en Japón hace unos meses, setenta años después de la muerte del cantor. El tiempo parece surgir del modo de funcionar de nuestra mente. La memoria es como una enciclopedia en la que figura Colón muriendo en Valladolid, naciendo en Génova, regresando de su tercer viaje a América, solicitando ayuda a la reina Isabel; es decir, todo está registrado en presente. Sólo cuando leemos secuencialmente y filtramos la información con nuestro sentido, comprendemos que Colón primero nació, luego pidió ayuda, descubrió América y sólo al final murió en Valladolid. Si un perverso recortó una película foto por foto y las mezcló, sólo podemos reconstruirla poniendo las que muestran a tal actor vivo antes de las que lo muestran muerto, a la embarazada antes que a esa misma mujer amamantando al niño. Si bien la memoria parece ser una suerte de cebolla con varias capas de distinta antigüedad, no la tenemos ordenada cronológicamente. ${ }^{10}$ Pero interrumpo este tema, pues otros ponentes de este Seminario se ocuparán de memorias conscientes, inconscientes, de fácil acceso o interdictas.

${ }^{9}$ Cereijido 2001, 107.

${ }^{10}$ Véase Blanck-Cereijido y Cereijido 1988 y 1997. 
Joseph Goebbels (1897-1945) afirmaba - y explotaba - que si al pueblo se le repite una mentira un suficiente número de veces acaba por creerla. Es que la mentira y el engaño son biológicamente muy importantes y son casi tan antiguos como la vida misma. Un virus no tiene la maquinaria molecular necesaria para reproducirse y depende de que los receptores en la membrana de las células lo "reconozcan" como una molécula "amiga" y lo dejen penetrar. Por supuesto no podemos hablar aquí de engaños conscientes, pues ni el virus ni la célula tienen consciencia. Pero una polilla sobrevive si su color y textura se parece a la hoja en que se ha posado y pasa inadvertida para el pájaro que busca alimento; "finge" no estar ahí. Perseguidas por una araña, algunas especies de polillas se dan vuelta y muestran una mancha oscura circular en cada ala y consiguen que la cegatona araña se retire temerosa de que se trate del rostro de un animal mucho más grande que la polilla. Hay orugas que segregan y se untan con babas con la que pegotean pétalos y hojarasca, de modo que un depredador "ve" una verdadera viborita mucho mayor que la oruga y se abstiene de atacar. La selección natural viene escogiendo a esta oruga tramposa, porque los depredadores se encargan de ir eliminando a las orugas "no embusteras". La flor engaña al insecto para que vaya a nutrirse en sus pétalos, se le pegue polen en sus patas y vaya a fecundar otras plantas. Finalmente, los peores tóxicos son aquellos cuyas moléculas resultan muy parecidas a los metabolitos normales pues, justamente, el organismo no los puede distinguir, se engaña y se intoxica. Alacranes, arañas, víboras son maestros en engañar a nuestros canales iónicos con sus inhibidores; de lo contrario no podrían paralizarnos, nutrirse y sobrevivir.

En el nivel humano nos ponemos ropas, adoptamos peinados, sonreímos para inducir la idea de que somos más sanos, guapos, inteligentes, seguros, exitosos, en una palabra, "seleccionables". 
Un gobierno mencionará cifras e interpretaciones sobre la educación, economía, historia, operativos y ocultará otros, y a veces la lucha política recurre a hurgar y revelar la información sobre hechos non sanctos que el adversario oculta. Los usos del engaño hacen que abunden personajes que pretenden ser clarividentes, y hasta da lugar a mecanismos curiosos. Uno de los más célebres fue (o como veremos sigue siendo) Nostradamus. Maravillados de que Nostradamus haya predicho que en 1939 estallaría una guerra mundial, y que en la segunda mitad del siglo xx China resurgiría como potencia mundial, se investigó el caso y se encontró que hay un truco que se viene repitiendo de tanto en tanto desde hace siglos, y que consiste en afirmar que Nostradamus predijo esto y aquello, sin ningún documento que pruebe fehacientemente que Michel de Nostradamus lo haya dicho en su Rémy de Provence a comienzos del siglo XVI. Un escritor contemporáneo simplemente dice que Nostradamus vaticinó esto y aquello, a sabiendas de que nadie va a ir a cerciorarse de que en realidad lo hizo y figura en los antiguos libros sobre este "vidente".

Los antiguos europeos, como los de toda otra cultura, debían conocer el momento de la siembra, la cosecha, las lluvias, los solsticios, los ritos que debían cumplir con sus muertos, y por supuesto retenían procedimientos y fechas combinándolos en una mitología ad hoc. Por eso hoy los arqueólogos e historiadores rebuscan antiguos documentos, analizan viejas creen$\operatorname{cias}^{11}$ y festivales que ahora son rescatadas y revividas para alimentar incluso la industria turística. Dependiendo del momento del año en que uno viaja a cierto pueblito de Baviera o a un rinconcito de la Bretaña, encuentra representado cada año con creciente hiperrealidad las criaturas que, sobre todo durante la Edad Media, ${ }^{12}$ se transmutaron de dioses paganos

\footnotetext{
${ }^{11}$ Véase Eliade 1962 y Walter 1989.

${ }^{12}$ Véase Dumézil 1935-1936.
} 
en santos cristianos: san Martín, san Ursino, ${ }^{13}$ san Hilario, san Eloy, ${ }^{14}$ santa Brígida. Los estudios muestran de qué manera la festividad de Jano, dios romano de las puertas, se fue convirtiendo en las fiestas de San Juan y el por qué de las fogatas, y así con los orígenes paganos del Huevo de Pascua, el Árbol de Navidad, los renos de Papá Noel, el Puente de Aviñón, Roberto el Diablo, Cristóbal y su perro pues, como opina Philippe Walter, "en cuestiones de mitologías nada se pierde, todo se transforma".

Y no solamente no hay pérdidas, a veces la mitología sale ganando. Ya no recuerdo el nombre de la santa a quien cortaron los dedos de las manos en el siglo IV y hoy tiene tres docenas. Es que las tropas napoleónicas robaron las reliquias durante un saqueo, y muchos años después un piadoso caballero cristiano pagó una fortuna para rescatarlos y reintegrárselos a la Iglesia. Pero eso inspiró a los ladrones, e hizo que llegaran otros caballeros cristianos y... la santa ya cuenta con treinta y seis dedos. ¿Cómo saber cuáles son los verdaderos de una muchacha muerta hace un milenio y medio? Muy sencillo: por su contenido en carbono catorce. Pero por respeto a los feligreses se evita determinar correctamente la edad de los dedos midiendo la proporción entre carbono trece —el común-y el catorce, que es radiactivo, de modo que la relación ${ }^{14} \mathrm{C} /{ }^{13} \mathrm{C}$ va disminuyendo y sirve de reloj atómico. Hay en Italia un santo con dos cabezas y dos cuerpos. Se trata de un clérigo que asistió a un concilio en Francia, murió, y su cuerpo fue conservado en una cripta francesa. De pronto lo santifican, su pueblito natal reclama las reliquias, los franceses se resisten, porque argumentan que ahora les pertenecen, y cien años más tarde el Vaticano ordena que sean devueltas, pero a llegar al pueblito los italianos advierten que tiene la cabeza cercenada. ¡Trampa!

13 Véase Bernheimer 1952.

14 Véase Eliade 1977. 
Reclaman. "Sí, en efecto, aquí hay un cuerpo y una cabeza separada, conceden los franceses, ahí se los enviamos", pero si bien es muy fácil establecer cuál cuerpo corresponde a cuál cabeza, no es posible determinar cuál es el juego que corresponde al santo y se conservan ambos. Luego, una misma deidad (Baco, Deméter, Silvano) aparece en distintas comarcas del Mediterráneo en versiones ligeramente distintas. Y así andando, no sorprende que el antropólogo Claude Lévi-Strauss opinara que un mito es el mito más todas sus versiones.

\section{Biología del olvido}

Jorge Luis Borges imagina un Ireneo Funes, el Memorioso, con una memoria infalible, que recuerda con toda facilidad las volutas del agua agitada por un remo, un libro de versos en latín que ha leído una sola vez, y, por lo tanto, al retener tanta información, llenaba su cabeza con una increíble cantidad de trivialidades, al punto que le tomaba un día el recordar un día. Elocuentemente, Borges no hace de Funes un supersabio, ni siquiera un muchacho inteligente. Es que, además de ocupar una enorme cantidad de memoria con insignificancias, la memoria perfecta no sirve para pensar ni, sobre todo, para imaginar. Un ser humano con una memoria perfecta se hubiera extinguido rápidamente. Si un africano señalara "¡Cuidado, allá viene un león!" y huyera a ponerse a salvo, y un segundo, con una memoria perfecta dijera "Recuerdo muy bien al león que se comió a nuestro hermano. No es ese que se aproxima", este segundo africano probablemente moriría. Los griegos querían "olvidar" las diferencias entre triángulos y entre esferas, y hacer teoremas que valieran para todos los triángulos y todas las esferas. Platón buscaba esencias que, en el fondo, consisten en tomar todo el universo de un objeto dado (triángulos, esferas, humanos, bellezas) y, justamente, podarle lo no esencial. 
Así como nuestra memoria desecha trivialidades, también agrega aspectos necesarios. De lo contrario no habría metonimias, pues cuando alguien leyera "La Corona Británica anunció...", imaginaría una corona de oro parlante. La Teoría de la Gestalt ha demostrado que cuando alguien visita a un amigo postrado en el hospital, pero al llegar sólo ve su cara y su torso emergiendo por encima de la ropa de cama, no teme que eso sea todo lo que queda de él. Esta propiedad es incluso aprovechada en literatura. Franz Kafka suele no adjetivar, y hasta narra ciertas cosas truculentas con fingida cotidianidad, para que el contraste fuerce al lector a agregar la emoción correspondiente. En La colonia penitenciaria el director muestra al visitante una máquina atroz para torturar al condenado, con la neutralidad con que mostraría las bisagras de una puerta, pero de pronto se preocupa por el visitante "Perdón. ¿Se ha manchado usted?". En la película Hiroshima mon amour, Alain Resnais elige contar los horrores del bombardeo atómico a través de una pareja ocupada en hacer el amor. Todos ellos saben - o intuyen - que antes de almacenar la nueva información, nuestra memoria la completará, reparará, decorará, adecuará. Al parecer, todas nuestras palabras se originan en añejas metáforas que resultaron exitosas, de manera que si nuestra memoria no tuviera la facultad de fallar, no tendríamos lenguaje ni saldríamos con vida. Pero todo esto no logra ocultar que hoy los biólogos no tenemos la menor idea de cómo hace la memoria para eliminar lo no significativo, agregar cosas importantes y optimizar la utilidad de los recuerdos.

\section{Estamos en manos de un Doppelgänger}

Damos por sentado que "nosotros" somos los encargados de interactuar con "la-realidad-de ahí-afuera". Pero un corredor de 100 metros planos oye el tiro, parte y recién se percata de 
estar corriendo 250 milisegundos después del tiro. ¿Quién ordenó entonces su partida? Análogamente, un pianista no puede pensar a la velocidad necesaria en bajar este dedo, subir aquel, mantener quietos los demás. ¿Quién está tocando el piano? Los estudios neurobiológicos en los que se miden estos fenómenos con exactitud, muestran que, dada una señal, algún centro cerebral toma una decisión y mucho después "informa" a nuestra consciencia para que ésta se dé el gusto de sentir que es "ella" quien manda. En su jerga, el especialista llama Doppelgënger (Otro Yo) a quien decide, actúa, nos hace prestar atención, filtra y escoge. En último término, el Doppelgänger parece estar a cargo de custodiar nuestra memoria.

\section{Información, conocimiento, memoria y misterio}

Para que un sistema asimile información, ésta le debe causar alguna modificación en su estructura/manera de funcionar. Es el caso de tarjetas o monedas reconocidas por el teléfono, contraseñas, identificaciones. Una biblioteca, un archivo, una computadora, pueden guardar cantidades enormes de información, pero sólo la cabeza humana es capaz de transformarla en conocimiento.

Si ponemos una moneda o una tarjeta falsa, el sistema no la reconocerá y no sufrirá ningún cambio en su estructura/manera de funcionar; no le significarán nada. La vida nos cambia continuamente de estructura/manera de funcionar, por eso un forense puede determinar la edad de un feto, bebé, adolescente, muchacho, anciano con bastante aproximación. Se dará cuenta de que en la juventud hemos sufrido la fractura de un fémur, nos quitaron dos muelas, o hemos estado enfermos de tuberculosis. Puede establecer la edad a que falleció cierto faraón, y si murió por envenenamiento o de un traumatismo, con mucha más precisión de lo que pudieran haberlo establecido sus pro- 
pios médicos. Nosotros somos de pronto nuestra propia autobiografía. Una galaxia, una montaña, las ruinas de una ciudad, y toda la realidad son para la ciencia sus propias memorias.

Sólo mencionaré algunos de los retos que quedan por elucidar en el futuro: 1) El verde no huele y lo frío no suena. ¿Cómo hace entonces nuestro organismo para combinar la información de los diversos sentidos y ofrecernos una visión unificada de la realidad? 2) Ya sabemos hacer redes de supercomputadoras que almacenan más información que el cerebro humano y la procesan más velozmente, pero no tenemos la menor idea de cómo dotarlas de sentimientos. 3) Las mariposas monarca vuelan de México a Canadá y regresan exactamente al mismo sitio, o sea recuerdan los datos necesarios, pero dado que tardan varias generaciones en lograrlo (la que regresa es la tatara-tataranieta de la que partió) no sabemos de qué manera conservan la información ni cómo la transmiten de generación en generación. 4) Los humanos nos manejamos con una visión del mundo, que es una manera de interpretar la realidad, está afianzada en nuestra memoria y es extremadamente resistente al cambio. Esta resiliencia de la memoria ha sido seleccionada a lo largo de millones de años porque el atesorar lo aprendido ofrece ventajas indudables. Pero hoy en día el mundo en que vivimos cambia tan rápidamente que muchos de los hábitos y costumbres se van transformando rápidamente en prejuicios dañinos. Moisés esperó dos generaciones para entrar a la tierra prometida, pues no quería hacerlo con gente que tuviera mentalidad de esclavo.

Función, estructura, memoria

Los conocimientos presentados nos permiten regresar ahora a esa relación crucial entre función, estructura y memoria, en busca de una ligera profundización de lo discutido. 
Nos han enseñado que la vida depende de un suministro de energía. Por el contrario, hoy se sabe que la vida depende de un flujo de energía a través de la biosfera, es decir, no solamente el suministro inicial sino también la disipación final. ${ }^{15}$ Para entenderlo, basta imaginar un río de montaña que al fluir permite generar electricidad, y la electrificación da origen a un poblado con edificios, elevadores, iluminación, televisión, teléfonos, cines, gente que nace, trabaja, se divierte, muere. Por sí solo, el suministro de agua anegaría al pueblo; concomitantemente, por sí sola la disipación de agua secaría el río y acabaría con la vida y las estructuras. Un segundo ejemplo lo brindan esos muñecos de lona que hoy se usan de propaganda. Sólo cuando se les hace fluir aire a través de ellos son capaces de erguirse, bambolearse, agitar los brazos. Análogamente, el flujo de energía a través de los sistemas biológicos causa un complejísimo metabolismo, que da origen inexorablemente a estructuras dinámicas, en el sentido de que no son estáticas sino que cambian a lo largo del tiempo. Una semilla consiste, justamente, en una estructura con el flujo energético interrumpido, porque la desecación impide las reacciones bioquímicas y por eso no vive. Pero basta con que se humedezca para que las reacciones prosigan y se desarrolle un vegetal de manera formalmente análoga al desarrollo del poblado junto al río. La semilla guarda la memoria de qué vegetal se producirá cuando prosiga el flujo metabólico. Ese vegetal producirá eventualmente más semillas con la memoria necesaria para generar retoños específicos de frijoles o rosales.

En resumen: la ciencia considera que en la realidad no hay cosas, sino procesos que adoptan estructuras dinámicas. Las configuraciones de estas estructuras son muy sensibles a su historia, maneras de funcionar y tipo de perturbaciones. Son de pronto su propia historia. Así como hay maneras de perturbar la

${ }^{15}$ Cereijido 1980. 
estructura de una cuerda de guitarra o el parche de un tambor para que emitan un sonido que podemos reconocer, hay también maneras de perturbar un disco compacto para que "nos regrese" la melodía atesorada en su estructura. Las estructuras biológicas atesoran memorias de varios tipos, entre las que destacan la memoria genética capaz de originar un nuevo individuo, o la memoria mental capaz de evocar un recuerdo. Todo aquello que tiene gran valor (gemas, relojes, coñacs, dinero, abolengos, famas, historias) atrae tarde o temprano a ladronzuelos, censores, genocidas, mistificadores que sacan ventajas de adulterarlo. Por ser tan valiosa, la memoria mental no es excepción. Ya sabemos falsearla; lo que aún no logramos es entenderla cabalmente.

\section{REFERENCIAS}

Bernheimer, R., 1952. Wild Men in the Middle Ages, New York, Harvard University Press.

Blanck-Cereijido, F. y M. Cereijido, 1988. La vida, el tiempo y la muerte, México, FCE.

—, 1997. La muerte y sus ventajas, México, FCE.

Borges, J. L., 1956. "El milagro secreto" y "La muerte y la brújula", en Ficciones, Buenos Aires, Emecé.

Cereisido, M., 1980. Orden, equilibrio y desequilibrio, México, Nueva Imagen.

—, 2001. "The Biology of Time and Death", Biological Rhythm Research, 32:2, 107-115.

Damasio, A., 1999. The Feeling of What Happens: Body and Emotion in the Making of Consciousness, New York, Harcourt Brace.

DumÉzIL, G., 1935-1936. "Temps et Mythes", Recherches Philosophiques, 5, 235.

Eliade, M., 1962. Méphistophéles et l'Androgyne, Paris, Gallimard.

—, 1977. Forgerons et Alchimistes, Paris, Flammarion.

Walter, P., 1989. La Mémoire du Temps: fêtes et calendriers de Chrétien de Troyes à la Mort Artu, Paris, Champion. 